\section{Moving upstream in thrombosis}

\section{By Lauren Martz, Staff Writer}

Researchers at Tufts University School of Medicine think that inhibiting the MMP1/PAR1 pathway could be a more effective way to prevent arterial thrombosis than using therapeutics that modulate thrombin itself, and it could also decrease the chance of life-threatening bleeding side effects. ${ }^{1}$ Because the new intervention point in the platelet activation and aggregation pathway would be targeted acutely, it might also avoid the toxicities seen in chronic use of some MMP inhibitors.

Arterial thrombosis, which often presents in the form of myocardial infarction (MI) or stroke, occurs following the rupture of atherosclerotic plaques. One of the first events in the cascade is the exposure of platelets to subendothelial ollagen, which signals a pathway of platelet activation and aggregation that can lead to occlusive blood clots. ${ }^{2}$

Marketed anticoagulation therapies include heparin, which activates the enzyme anti-thrombin III (SERPINC1; AT3) to indirectly inhibit thrombin (F2), and direct thrombin inhibitors such as lepirudin. Both types of drugs are widely used and effective but have the potential to cause fatal bleeding. ${ }^{3}$

In a paper published in Cell, Athan Kuliopulos and colleagues at Tufts suggested that targeting activation of matrix metalloproteinase 1 (MMP1) could prevent thrombus formation with a lower chance of causing bleeding side effects.

The team showed that exposing human platelets to collagen causes activation of MMP1 on the surface of platelets. Activated MMP1 then cleaves and activates the thrombin receptor protease-activated receptor 1 (PAR1) and leads to platelet aggregation. Blocking MMP1 or PAR1 in the collagen-stimulated platelets prevented their activation, suggesting that it might also prevent thrombosis.

Thrombin inhibitors had no such effect, likely because thrombin is not yet released at the time that platelets contact collagen.

In a guinea pig model of carotid artery injury, inhibition of MMP1 or PAR1 increased mean occlusion time by about $50 \%$.

"Preventing occlusion is the goal," said Kuliopulos, who is an associate professor of medicine and biochemistry and director of the hemostasis and thrombosis laboratory at Tufts. "However, due to variability of large animal vessel occlusion, one uses mean time to occlusion. A delayed occlusion should correlate with clinical significance given the severity of the injury."

Kuliopulos told SciBX that there are no small molecules targeting collagen-dependent platelet activation. He said his team is "in lead optimization and will select the best candidate to move into human studies."

He added that preclinical studies will determine whether a small molecule inhibitor of MMP1 or PAR1 is chosen.

\section{Seeking advantages}

Regardless of which type of inhibitor Kuliopulos' group takes into the clinic, the hope is that working upstream of thrombin could leave other aspects of the coagulation pathway intact to prevent bleeding.

"Patients with a prior history of bleeding or cerebrovascular conditions cannot take direct thrombin inhibitors," he noted. "Preventing the direct inhibition of thrombin would allow its other activities to occur, such as the cutting of fibrinogen to form fibrin, which is necessary to prevent bleeding incidents."

The researchers also think their approach could result in better efficacy than that of marketed drugs because MMP1/PAR1 activation is one of the first events that occurs following plaque rupture.

Kuliopulos said collagen is a potent activator of platelets and is the first thing platelets encounter when a plaque ruptures. Collagen activates MMP1, which then cuts PAR1, and this all happens before thrombin is even generated.

"We can say that current treatments are only partially effective, so the exciting possibility that a new therapeutic mechanism could cover more territory of the thrombogenic pathway is worth pursuing," said Jeffrey Johnson, principal scientist of biology at Metabolex Inc.

In 2005, Metabolex and Pfizer Inc. performed proof-of-concept studies with the broad-spectrum MMP inhibitor PD166793 and showed that it prevented rodents from developing diabetes. MMPs have been shown to be dysregulated in diabetes.

Despite the mechanistic rationale for pursing MMP1 or PAR1 inhibitors, Karl-Uwe Petersen, VP of preclinical development at Paion AG's Paion Deutchland GmbH subsidiary, told SciBX that a comparison to existing compounds, such as thrombin, would be good to have.

"You would have to profile the drug designed by this mechanism against existing drugs for the indication, and it will have to be shown to be better, and particularly safer," he said.

Paion's Flovagatran is a direct thrombin inhibitor in Phase II testing for thrombosis.

\section{Strength in specificity}

If the Tufts group opts to develop an MMP1 inhibitor to prevent thrombosis, it could be a tall order to find a compound that specifically hits a single MMP. 


\section{TARGETS \& MECHANISMS}

According to Kuliopulos, there are about 24-26 MMPs, all of which have similar active sites. Due to this similarity, most MMP inhibitors affect several of the enzymes and thus can produce off-target effects.

"In past cancer studies, two or three broad-spectrum MMP inhibitors were tested. They were used chronically at high doses and caused side effects that were mostly musculoskeletal, such as joint toxicities," Kuliopulos noted.

Marimastat, a broad-spectrum MMP inhibitor, failed to show benefit over chemotherapy in Phase III trials for several types of cancers between 1999 and 2001. The compound, from British Biotech plc, now part of Vernalis plc, also was associated with musculoskeletal pain.

"Broad MMP inhibitors have failed due to musculoskeletal syndrome (pain), and selective MMP1 inhibitors have failed due to lack of human efficacy for the indications tested," said Johnson.

Roche's Trocade illustrated the latter point. The MMP1 inhibitor had favorable tolerability and pharmacokinetics but lacked efficacy in clinical trials for rheumatoid arthritis (RA).,5

Johnson noted that in the case of MMP inhibition for diabetes, the next step also would have to be developing more selective inhibitors to avoid side effects and improve efficacy.

In thrombosis, Kuliopulos said an MMP1 inhibitor would likely not cause muscle toxicity because it would be used in acute settings such as percutaneous intervention.

"An MMP1 or PAR1 inhibitor could be used as an acute part of the intervention-for the first one or two days before Plavix or aspirin can take over," he said. Bristol-Myers Squibb Co. and sanofi-aventis Group market Plavix clopidogrel.

Indeed, in an acute application, "they could theoretically give a bolus dose without the side effects of long-term treatment," noted Philip Barr, founder and CSO of Arriva Pharmaceuticals Inc.

Arriva's Ilomastat, an inhaled small molecule MMP inhibitor, is in preclinical testing to treat chronic obstructive pulmonary disease (COPD) and emphysema. Based on the animal models, Barr said the calculated efficacious dose in humans could be three orders of magnitude lower than the typical systemic MMP inhibitor dose.

Kuliopulos told SciBX that several patents have been filed covering the findings in the paper. The IP is available for licensing.

Martz, L. SciBX 2(17); doi:10.1038/scibx.2009.690

Published online April 30, 2009

\section{REFERENCES}

1. Trivedi, V. et al. Cell; published online April 16, 2009; doi:10.1016/j.cell.2009.02.018

Contact: Athan Kuliopulos, Tufts University School of Medicine, Boston, Mass.

e-mail: athan.kuliopulos@tufts.edu

2. Moers, A. et al. Nat. Med. 9, 1418-1422 (2003)

3. Gallus, A. \& Hirsh, J. Drugs 12, 41-68 (1976)

4. Hemmings, F. et al. Rheumatology 40, 537-543 (2001)

5. Close, D.R. Ann. Rheum. Dis. 60, iii62-iii67 (2001)

\section{COMPANIES AND INSTITUTIONS MENTIONED}

Arriva Pharmaceuticals Inc., Alameda, Calif. Bristol-Myers Squibb Co. (NYSE:BMY), New York, N.Y. Metabolex Inc., Hayward, Calif.

Paion AG (Xetra:PA8), Aachen, Germany Pfizer Inc. (NYSE:PFE), New York, N.Y.

Roche (SIX:ROG), Basel, Switzerland sanofi-aventis Group (Euronext:SAN; NYSE:SYN), Paris, France Tufts University School of Medicine, Boston, Mass. Vernalis plc (LSE:VER), Winnersh, U.K. 